\title{
TOTAL INFERIOR TURBINECTOMY VERSUS INFERIOR TURBINOPLASTY- A COMPARATIVE STUDY
}

Sathish Kumar K. N1, Akash Aradhya $S^{2}$

${ }^{1}$ Assistant Professor, Department of ENT, MMCRI, Mysuru, Karnataka, India.

2Postgraduate Student, Department of ENT, MMCRI, Mysuru, Karnataka, India.

\section{BACKGROUND}

ABSTRACT

Chronic nasal obstruction due to hypertrophy of the inferior turbinate is a very common problem encountered by otolaryngologist. Several surgical procedures have been suggested to deal with hypertrophy of the inferior turbinate.

This study was conducted to evaluate and compare the efficacy and complications of two of the widely practised surgical procedures, total inferior turbinectomy and inferior turbinoplasty.

\section{MATERIALS AND METHODS}

This is a non-randomised trial. Fifty patients with chronic nasal obstruction due to associated inferior turbinate hypertrophy were selected for the study. They were divided into two groups with 25 patients in each group. One group underwent total inferior turbinectomy with concomitant septoplasty and the other inferior turbinoplasty with concomitant septoplasty.

\section{RESULTS}

Significant improvement in nasal obstruction was noticed in both the groups. Out of 50 patients with nasal obstruction, 47 patients (94\%) were relieved of the symptoms, of which $24 / 25$ patients (96\%) and 23/25 (92\%) patients were present in total inferior turbinectomy and inferior turbinoplasty groups respectively. Significant difference in terms of complications was noticed between the two types of surgery.

\section{CONCLUSION}

Both total inferior turbinectomy and inferior turbinoplasty are effective surgical procedures for the management of inferior turbinate hypertrophy. Inferior turbinoplasty is technically more difficult, but has less number of complications. Further follow-up study with large number of subjects is necessary to assess the long-term effectiveness and complications of total inferior turbinectomy.

\section{KEY WORDS}

Total Inferior Turbinectomy, Inferior Turbinoplasty, Gertner-Podoshin Plate.

HOW TO CITE THIS ARTICLE: Kumar SKN, Aradhya AS. Total inferior turbinectomy versus inferior turbinoplasty- a comparative study. J. Evolution Med. Dent. Sci. 2018;7(35):3830-3834, DOI: 10.14260/jemds/2018/859

\section{BACKGROUND \\ Inferior turbinate hypertrophy is one of the major causes of chronic nasal obstruction. Although, it is not a life- \\ reduction surgeries, total inferior turbinectomy and inferior turbinoplasty and to suggest a suitable surgical procedure depending upon the result of the study.} threatening condition, nasal obstruction due to inferior turbinate hypertrophy can interfere with the quality of life. Surgery is considered when patients are not responding to medical treatment. Various methods of surgical management of inferior turbinate hypertrophy have been suggested including total inferior turbinectomy, partial inferior turbinectomy, submucosal resection of turbinate, inferior turbinoplasty, outfracture of inferior turbinate, cryotherapy, electrocautery, laser turbinectomy and argon plasma surgery. But none of the above-mentioned procedures give universally satisfactory result. Various complications like crusting, dryness, adhesions and atrophic rhinitis have been reported following turbinate reduction surgery. This study was designed to study the efficacy, advantages, disadvantages and complications of two of the widely practised turbinate

'Financial or Other Competing Interest': None.

Submission 26-07-2018, Peer Review 09-08-2018,

Acceptance 11-08-2018, Published 27-08-2018.

Corresponding Author:

Dr. Sathish Kumar K. N,

\#C-178, Panchavati, $5^{\text {th }}$ Cross,

Adarsha Nagar, Hassan-573201,

Karnataka, India.

E-mail: sathishroanann@yahoo.com

DOI: $10.14260 /$ jemds/2018/859

\section{Aims and Objectives}

To compare the surgical results of total inferior turbinectomy with that of inferior turbinoplasty regarding subjective and objective improvement and complications.

\section{MATERIALS AND METHODS \\ Study Design}

This is a non-randomised trial, carried out over a period of one year from January 2017 to December 2017 at KR Hospital, Mysuru. Patients attending the outpatient department of ENT with inferior turbinate hypertrophy with or without DNS who fulfil the inclusion criteria were included in the study.

Patients were divided into two groups of patients in each group. Group A underwent bilateral total inferior turbinectomy with or without septoplasty and Group B underwent bilateral inferior turbinoplasty with or without septoplasty. Selection of patients was done by nonrandomisation using non-random number table. Patients were followed up preoperatively and postoperatively.

\section{Sample Size}

It was a time bound study and based on the statistics of previous year (2016) the number of turbinate surgeries done 
was approximately 50 cases. Considering the statistics, sample size of 50 was decided.

\section{Inclusion Criteria}

Patients with chronic nasal obstruction due to bilateral inferior turbinate hypertrophy refractory to medical therapy with or without deviated nasal septum.

\section{Exclusion Criteria}

- Patients with infective rhinosinusitis, nasal polyposis and various tumours and granulomatous conditions of nasal cavity.

- $\quad$ Patients less than 17 years of age.

\section{Statistical Methods}

Data was entered into Microsoft Excel data sheet and was analysed using SPSS 22 (IBM SPSS Statistics, Somers, NY, USA) version software. Categorical data was represented in the form of frequencies and proportions. Chi-square test was used as test of significance for qualitative data. Continuous data was represented as mean and standard deviation. Pvalue (probability that result is true) of $<0.05$ was considered as statistically significant after assuming all the rules of statistical tests.

\section{Method of Collection of Data}

- Cases selected for the study were subjected to detailed history and clinical examination.

- They were assessed subjectively and objectively.

- Subjective assessment was done by asking about the symptoms of nasal obstruction, nasal discharge, hyposmia, post nasal discharge, headache and sneezing.

- Objective assessment was done by measuring nasal patency using the Gertner-Podoshin plate before and after the surgery. The Gertner-Podoshin plate is a simple method of measuring the breathing function of the nose. ${ }^{1}$ The instrument itself is a polished metal chromic coated plate of $10 \times 12 \mathrm{~cm}$ large. The plate is marked with arches of $1 \mathrm{~cm}$ apart.

The method is based on measuring the area of vapour condensed on the plate. The difference in temperatures between the breath from the nose and the plate allows the vapour in the air to be condensed on the colder metal plate, which must be held under the nostrils in a horizontal position in such a way that the vertical axis of the plate is 90 degrees towards the upper lip and straight under the columella. The patient is instructed to breathe through the nose slowly without force and with a closed mouth. In this way we can measure the breathing function of the nose, by measuring the area of condensed vapour on the metal plate as based on the formula: $S=\prod$ a.b. Values are mentioned in round figures (e.g. Surface area of $2.82 \mathrm{cms}$ is mentioned as $3 \mathrm{~cm}$ ).

\section{Cases were investigated in the following manner}

- Routine haemogram.

- Diagnostic nasal endoscopy.

- X-ray PNS to rule out sinus diseases.

After complete preoperative assessment, patients were subjected to surgical intervention. Patients were nonrandomly divided into two groups, one group underwent total inferior turbinectomy with or without septoplasty and the other group underwent total inferior turbinoplasty with or without septoplasty.

\section{Procedure}

Patents were admitted one day prior to surgery. All surgeries were done under general anaesthesia. On the day of surgery, both nasal cavities of the patient were packed with ribbon gauze soaked in $4 \%$ xylocaine with adrenaline. Local infiltration containing $2 \%$ xylocaine with 1 in 200000 adrenaline was given submucosally over the inferior turbinate on both the sides and over the septum and the following was done for the respective groups.

In Group A, using Killian's nasal speculum and fibreoptic headlight inferior turbinate was visualised and then crushed along its line of attachment and simultaneously fractured in a superior direction. Then the turbinate, hanging only by its layer of mucosa was trimmed with turbinate scissors. ${ }^{2}$ The turbinate was taken out and bleeding was controlled by packing the nasal cavity with ribbon gauze soaked in $4 \%$ xylocaine with adrenaline for few minutes. Same procedure was repeated on the other side and concomitant septoplasty was done for all cases as we noticed at least minimal DNS in all the patients selected for surgery. Nose was packed with regular nasal packing.

In Group B, incision was made using a number 15 blade along the inferior edge of the turbinate through the mucosa and stroma. The medial mucosal flap was elevated from the turbinate bone followed by outfracturing of the inferior turbinate bone. The turbinate scissors was used to excise the bone along with its lateral wall mucosa of the anterior twothirds of the turbinate. Ribbon gauze soaked in $4 \%$ xylocaine with adrenaline was kept for few minutes in the cavity to control bleeding. Pack was removed, and medial mucosal flap of the turbinate was rolled upon itself from medial to lateral to form neoturbinate. The flap was crushed laterally. ${ }^{3}$ Same procedure was done on the other side and concomitant septoplasty was done for all the cases. Nose was packed with regular nasal packing.

\section{Post-Operative Management}

Nasal packs were removed 24 hours after the surgery. Patients were put on antibiotics for one week along with analgesics and decongestants.

Patients were discharged on first postoperative day and were advised to come for follow-up on fifteenth day and at the end of two months.

At each follow-up visit, subjective and objective assessments were done. Subjective assessment was done using patient questionnaires and objective assessment was done using Gertner-Podoshin plate.

With the above findings, the outcomes of surgery were measured and statistically analysed using Chi-square test $\left(\mathrm{x}^{2}\right)$.

\section{RESULTS}

A total of 50 patients were enrolled in our study, divided into two groups of patients. Group A underwent TIT (Total Inferior Turbinectomy) with or without septoplasty and Group B underwent ITP (Inferior Turbinoplasty) with or without septoplasty. 


\section{Age Distribution}

In our study, the ages of patients varied from 19 years to 55 years with a mean age of 27.82. In Group A, ages varied from 19 to 52 years with a mean age of 27.52. In Group B, ages varied from 19 to 55 years with a mean age of 28.12 .

\section{Sex Distribution}

In this series, there were 26 males (52\%) and 24 females (48\%).

In Group A, there were 13 males (52\%) and 12 females (48\%). In Group B, there were 13 males (52\%) and 12 females (48\%).

\section{Subjective Assessment}

In our study preoperatively, all the 50 patients (100\%) had nasal obstruction. Postoperatively, there was significant improvement in nasal obstruction in both groups. Out of 50 patients with nasal obstruction, 47 patients (94\%) were relieved of the symptoms of which 24 out of 25 patients (96\%) and 23 out of 25 (92\%) patients were present in turbinectomy and turbinoplasty groups respectively.

The next common symptom was nasal discharge, which was present in 30 patients $(60 \%)$ divided into 16 cases (64\%) in turbinectomy group and 14 cases (56\%) in turbinoplasty preoperatively. Postoperatively, on the $15^{\text {th }}$ day after surgery $6 / 16$ patients (benefit $62.5 \%$ ) had nasal discharge in turbinectomy group and 8/14 patients (benefit $42.86 \%$ ) had nasal discharge in turbinoplasty group with an overall benefit of $53.33 \%$. Third common symptom was hyposmia, present in 14 patients divided into 7 patients in each group (28\% in each group). Postoperatively, hyposmia was complained by $2 / 7$ patients (benefit $71.43 \%$ ) in inferior turbinectomy group and $2 / 7$ patients (benefit $71.43 \%$ ) in turbinoplasty group with overall $71.43 \%$ benefit. Postnasal discharge was present in 10 patients $(20 \%)$ divided into 6 patients (24\%) in turbinectomy group and 4 patients (16\%) in turbinoplasty group. Postoperatively, post nasal discharge was present in $2 / 6$ patients (benefit $66.67 \%$ ) in turbinectomy group and 2/4 patients (benefit 50\%) in turbinoplasty group. Headache was present in only 6 patients $(12 \%)$, of which 3 patients $(12 \%)$ were in turbinectomy group and 3 patients (12\%) were in turbinoplasty group. Postoperatively, headache was still complained by one-third of the patients (benefit 66.6\%) in turbinectomy group and one-third of the patients $(66.6 \%)$ in turbinoplasty group with an overall benefit of $66.67 \%$. Least common symptom was sneezing present in 5 patients (10\%), of which 3 patients (12\%) were in turbinectomy group and 2 patients (8\%) were in turbinoplasty group. Postoperatively, sneezing was present in $1 / 3$ patients (benefit $66.67 \%$ ) in turbinectomy group and $1 / 2$ patients (benefit 50\%) in turbinoplasty group with an overall benefit of $60 \%$.

\section{Objective Assessment}

Patients were divided into 4 groups according to nasal airflow as measured by the Gertner-Podoshin plate. Group 1 with severe nasal obstruction, Group 2 with moderate nasal obstruction, Group 3 with mild nasal obstruction and Group 4 with very mild nasal obstruction.

\begin{tabular}{|c|c|c|c|c|c|}
\hline Group & $\begin{array}{c}\text { Nasal } \\
\text { Airflow } \\
\text { cm }\end{array}$ & $\begin{array}{c}\text { TIT } \\
\text { No. of } \\
\text { Patients }\end{array}$ & Percentage & $\begin{array}{c}\text { ITP } \\
\text { No. of } \\
\text { Patients }\end{array}$ & \\
\hline 1 & $0-1$ & 2 & $8 \%$ & 4 & $16 \%$ \\
\hline 2 & $2-3$ & 15 & $60 \%$ & 13 & $52 \%$ \\
\hline 3 & $4-5$ & 7 & $28 \%$ & 7 & $28 \%$ \\
\hline 4 & $6-9$ & 1 & $4 \%$ & 1 & $4 \%$ \\
\hline \multicolumn{7}{|c|}{ Table 1. Pre-operative objective assessment of Nasal } \\
Airflow \\
\hline
\end{tabular}

Postoperatively, there were 2 patients (8\%) with a patency of $0-1 \mathrm{~cm}$ in turbinectomy group and 4 patients (16\%) with a patency of $0-1 \mathrm{~cm}$ in turbinoplasty group. There were 15 patients $(60 \%)$ with a patency of $2-3 \mathrm{~cm}$ in turbinectomy group and 13 patients (52\%) with a patency of $2-3 \mathrm{~cm}$ in turbinoplasty group. Seven patients (28\%) with a patency of $4-5 \mathrm{~cm}$ were present in both turbinectomy and turbinoplasty groups. There was only 1 patient (4\%) with a patency of $6-9 \mathrm{~cm}$ in both turbinectomy group and turbinoplasty group.

\section{Objective Assessment after Surgery}

Postoperatively, objective assessment was done on the $15^{\text {th }}$ postoperative day, i.e. during their first postoperative visit and again after 2 months i.e. during their $2^{\text {nd }}$ postoperative visit. Postoperatively, on the $15^{\text {th }}$ postoperative day, no patients in our study had nasal patency of $0-1 \mathrm{~cm}$. There were 2 patients with a nasal patency of $2-3 \mathrm{~cm}$ divided into 1 patient (4\%) in turbinectomy group and 1 patient (4\%) in turbinoplasty group. Six patients (24\%) in turbinectomy group and 7 patients (28\%) in turbinoplasty group had a patency of $4-5 \mathrm{~cm}$. There were 35 patients with a patency of $6-9 \mathrm{~cm}$ divided into 18 patients (72\%) in turbinectomy group and 17 patients (68\%) in turbinoplasty group.

Though, there was no significant difference in the postoperative objective improvement between the two types of surgery, the difference between the preoperative and postoperative states in both types of treatment was statistically significant $(\mathrm{p}<0.05)$.

The next objective assessment was made 2 months after the surgery. During this assessment the findings in terms of patency were same as that of first postoperative visit on the $15^{\text {th }}$ postoperative day. Statistical analysis showed no significant difference between the two operations ( $p>0.05$ ).

\begin{tabular}{|c|c|c|c|c|}
\hline \multirow[b]{2}{*}{$\begin{array}{c}\text { Nasal } \\
\text { Airflow in } \\
\text { cm }\end{array}$} & TIT & \multirow[b]{2}{*}{$\begin{array}{c}\text { Patients } \\
\text { after } 2 \\
\text { Months }\end{array}$} & \multirow{2}{*}{$\begin{array}{c}\text { ITP } \\
\text { Patients } \\
\text { after } 15 \\
\text { Days }\end{array}$} & \multirow[b]{2}{*}{$\begin{array}{c}\text { Patients } \\
\text { after } 2 \\
\text { Months }\end{array}$} \\
\hline & $\begin{array}{c}\text { Patients } \\
\text { after } 15 \\
\text { Days }\end{array}$ & & & \\
\hline $0-1$ & $0(0 \%)$ & $0(0 \%)$ & $0(0 \%)$ & $0(0 \%)$ \\
\hline $2-3$ & $1(4 \%)$ & $1(4 \%)$ & $1(4 \%)$ & $1(4 \%)$ \\
\hline $4-5$ & $6(24 \%)$ & $6(24 \%)$ & 7 (28\%) & $7(28 \%)$ \\
\hline $6-9$ & $18(72 \%)$ & $18(72 \%)$ & $17(68 \%)$ & $17(68 \%)$ \\
\hline \multicolumn{5}{|c|}{$\begin{array}{c}\text { Table 2. Postoperative objective assessment of Nasal } \\
\text { Airflow }\end{array}$} \\
\hline
\end{tabular}

\section{Complications}

Postoperative complications observed during our study are summarised in the table below. 


\begin{tabular}{|c|c|c|c|c|c|c|}
\hline Complications & \begin{tabular}{|c|} 
TIT \\
Cases \\
\end{tabular} & $\%$ & \begin{tabular}{|c|} 
ITP \\
Cases \\
\end{tabular} & $\%$ & Total & $\%$ \\
\hline Haemorrhage & 8 & 32 & 2 & 8 & 10 & 20 \\
\hline $\begin{array}{c}\text { Poor wound } \\
\text { healing }\end{array}$ & 8 & 32 & 1 & 4 & 9 & 18 \\
\hline Synechiae & 4 & 16 & 3 & 12 & 7 & 14 \\
\hline Crusting & 2 & 8 & 1 & 4 & 3 & 6 \\
\hline Dryness & 1 & 4 & 0 & 0 & 1 & 2 \\
\hline
\end{tabular}

In our study 8 patients (32\%) in turbinectomy group had postoperative bleeding, while the postoperative bleeding was observed only in 2 patients from the turbinoplasty group. Statistical analysis by Chi-square test showed a significant difference in complications between the two operations $\left(\mathrm{x}^{2}\right.$ value $=4.50: \mathrm{p}<0.05$ ). Poor wound healing was noticed in 8 patients (32\%) belonging to turbinectomy group, while the same complication was noticed in only 1 patient $(4 \%)$ from the turbinoplasty group. Statistical analysis by Chi-square test showed a significant difference in wound healing between the two operations $\left(x^{2}\right.$ value $\left.=6.64: p<0.05\right)$.

Synechiae was observed in 4 patients $(16 \%)$ from the turbinectomy group and 3 patients $(12 \%)$ from the turbinoplasty group.

Crusting was observed in two patients (8\%) from the turbinectomy group and 1 patient (4\%) from the turbinoplasty group.

Dryness as a postoperative complication was noticed in only one patient in our study, who belonged to turbinectomy group.

\section{DISCUSSION}

The present study conducted at KR Hospital, Mysuru from January 2017 to December 2017 included 50 patients, divided into two groups. One group underwent total inferior turbinectomy and the other group underwent inferior turbinoplasty.

Our study included two well-matched groups of patients, as there is no difference in mean age and sex between two groups.

In a study conducted by Ophir D, Shapira A and Marshak Gabriel, all the patients $(100 \%)$ had nasal obstruction followed by nasal discharge in 57 patients (57\%) and headache in 41 patients $(41 \%){ }^{4}$

Our study correlates well with the above-mentioned study. In our study, all the 50 patients $(100 \%)$ had complaints of nasal obstruction followed by nasal discharge in 30 patients $(60 \%)$, hyposmia in 14 patients $(28 \%)$, postnasal discharge in 10 patients $(20 \%)$, headache in 6 patients $(12 \%)$ and sneezing in 5 patients (10\%).

In our study, 24 patients (96\%) who underwent turbinectomy were relieved of nasal obstruction and 23 patients (92\%) who underwent turbinoplasty were relieved of nasal obstruction after the surgery. There was no significant difference in improvement between two types of surgeries.

Ten patients (62.5\%) had relief from nasal discharge after turbinectomy and 6 patients (42.86\%) had relief from nasal discharge after turbinoplasty. There was significant improvement in hyposmia after turbinectomy (71.43\%) and also after turbinoplasty (71.43\%). But there was no significant difference in improvement between two types of surgery.

There was improvement in other symptoms, i.e. postnasal discharge, headache and sneezing, but no significant conclusion could be drawn as the number of patients was less.

Objective assessment was made using Gertner-Podoshin plate 2 weeks after the surgery and again 2 months after the surgery. In our study though there was no significant difference in nasal airflow measurement between the two surgeries, the difference between the preoperative and postoperative states in both types of treatment was statistically significant $(\mathrm{p}<0.05)$.

\section{Complications}

In our study, bleeding was observed in 8 patients (32\%) belonging to turbinectomy and 2 patients (8\%) belonging to turbinoplasty group. In all cases, bleeding occurred within 24 hours following surgery. Statistical analysis by Chi-square test showed significant difference between the two types of surgery $\left(\mathrm{x}^{2}\right.$ value $\left.=4.50 ; \mathrm{p}<0.05\right)$. Bleeding was controlled in all patients and no patient required blood transfusion. Poor wound healing was noticed in 8 patients (32\%) belonging to turbinectomy group and in only one patient $(4 \%)$ in turbinoplasty group. Statistical analysis showed significant difference in postoperative wound healing between the two types of surgery $\left(\mathrm{x}^{2}\right.$ value $\left.=6.64 ; \mathrm{p}<0.05\right)$.

Synechiae was seen postoperatively in 4 patients $(16 \%)$ after turbinectomy and in 3 patients (12\%) after turbinoplasty. There was no significant difference between the two groups.

Crusting was observed in 2 patients (8\%) after turbinectomy and 1 patient (4\%) after turbinoplasty. Dryness was observed in only one patient after turbinectomy and was not observed after turbinoplasty.

Martinez et al reported a study on 29 patients who underwent turbinectomy and observed postoperative bleeding in 3 patients and dryness and crusting in 1 patient. 5

In another study conducted by Fradis et al, bleeding occurred in $20 \%$ of patients and crusting occurred in $10 \%$ of patients following turbinectomy. ${ }^{6}$ Our study correlates well with the above-mentioned studies.

\section{CONCLUSION}

From the results of our study, we conclude that both total inferior turbinectomy and inferior turbinoplasty are effective surgical procedures in relieving nasal obstruction due to hypertrophy of inferior turbinate. The complications noticed in the present study were not severe and were manageable, though they were more common in inferior turbinectomy group. Further follow-up study with a larger number of subjects is necessary to assess the long-term effectiveness and complications of inferior turbinectomy.

\section{REFERENCES}

[1] Gertner R, Podoshin L, Fradis M. A simple method of measuring the nasal airway in clinical work. The Journal of Laryngology and Otology 1984;98(4):351-5.

[2] Talmon Y, Samet A, Gilbey P. Total inferior turbinectomy: operative results and technique. Ann Otolaryngol 2000;109(12 Pt 1):1117-9.

[3] Mabry RL. "How I do it"- plastic surgery. Inferior turbinoplasty. Laryngoscope 1982;92(4):459-61. 


\section{Jemds.com}

[4] Ophir D, Schindel D, Halperin D, et al. Long-term follow-up of effectiveness and safety of inferior turbinectomy. Plastic and Reconstructive Surgery 1992;90(6):980-4.

[5] Martinez SA, Nissen AJ, Stock CR, et al. Nasal turbinate resection for relief of nasal obstruction. Laryngoscope 1983;93(7):871-5.
Original Research Article

[6] Fradis M, Golz A, Danino J, et al. Inferior turbinectomy versus submucosal diathermy for inferior turbinate hypertrophy. Ann Otol Rhino Laryngol 2000;109(11):1040-5. 